\title{
Çin'deki Azınlıklar için 20. yy. İki Dilli Eğitim Politikaları Üzerine Bir İnceleme
}

\author{
Arş. Gör. Çile Maden Kalkan \\ Ankara Hacı Bayram Veli Üniversitesi, Edebiyat Fakültesi \\ Mütercim Tercümanlık Çince Bölümü \\ cile.maden@hbv.edu.tr
}

Öz

Kaynağını toplumbilim ve dilbilimden alan iki dillilik, özellikle de dilbilimin hızla gelişen karmaşık bir alanıdır. Çin dilinin zorluğu uzun yıllar boyunca dilin sürekli olarak hükümet tarafından sadeleştirilmesi çalışmalarını da beraberinde getirmiştir ancak dilin bu sadeleştirme hareketi, kırsal kesimlerdeki azınlıklar için durumu daha zor bir hale getirmiştir. Bu çalışmanın amacı; iki dillilik ve bunun olumlu-olumsuz sonuçlarını Çin'deki azınlıklar üzerinden değerlendirmektir. Çalışmada, tarihsel süreç içerisinde hükümetin eğitim-öğretimde aldığı karar ve yasalara başvurulmuştur. Hükümetin bu konudaki tutumunun yanı sıra Çinli bilim insanlarının iki dilli eğitime bakış açıları araştırılıp, iki dilli eğitim politikaları ve bunların Çin azınlık okullarında uygulanması incelenmiştir. Bu çalışmada; dar anlamda azınlıklar için kendi dillerine ek olarak ikinci bir dilin ortaya çıktığı ve bu süreçteki zorlukların hükümetin eğitim politikalarıyla desteklenerek giderilmeye çalışıldığı; geniş anlamda ise toplumda pasif gruplar için çok dilli eğitim, baskın gruplar için de çok kültürlü eğitimin iki yönlü işlevselleştirilmesi gerektiği sonucuna varılmıştır.

Anahtar Kelimeler: Çin, iki dilli, iki dillilik, azınlıklar, eğitim politikaları.

\section{A Study of Bilingual Education Policies for Minorities in China in the $20^{\text {th }}$ Century}

\begin{abstract}
Bilingualism, which derives its origins from sociology and linguistics, is a rapidly developing and complex field of linguistics in particular. The diffuculty of the Chinese language has led to the constant government simplification of the language for many years, but this simplification of the language has made the situation more difficult for minorities in rural areas. The aim of this study is, to evaluate bilingualism and its positive and negative consequences over minorities in China. In the study, the decisions and laws of the government during the historical process were used. In addition to the attitude of the government on this issue, the perspectives of Chinese scholars on bilingual education were investigated, and bilingual education policies and their implementation in Chinese minority schools were examined. In this study in a narrow sense, a second language emerged for minorities in addition to their own and the difficulties in this process were tried to be overcome by supporting the government's education policies; in a broad sense, it was concluded that multilingual education for passive groups in society and multicultural education for dominant groups should be functionalized in two ways.
\end{abstract}

Keywords: China, bilingual, bilingualism, minorities, education policies. 


\section{GİRIŞ}

Çin, 56 etnik gruptan oluşan bir ülkedir. Han ${ }^{1}$ (汉) çoğunluğu toplam nüfusun yaklaşık \%92'sini oluştursa da 55 azınlık grup 91 milyonluk nüfusuyla bu toplamın \%8'ini oluşturmaktadır. Han Çinlileri ile karşılaştırıldığında nispeten az sayılarına rağmen azınlık halkları, başka ülkelerle sınır olan Çin topraklarının \%60'ında bulunurlar. Nüfusun büyük çoğunluğunu azınlıkların oluşturduğu bazı illerdeki etnik gerginlikler, siyasi istikrarsızlığın da önemli bir nedeni olmaktadır. Bu nedenle ülkede birliği korumak için 1980 yılından bu yana hükümet belli politikalar ileri sürmüştür (Lin, 1993, s. 5-21).

Sınırlı yerel özerklik ve kontroller, hükümet ile azınlık grupları arasındaki ilişkiyi karakterize etmektedir. 1950'lerde etnik azınlıkların özel olarak tanınmaları ve saygı gösterildiğini kanıtlamak için, Sincan (新疆), İç Moğolistan, Tibet, Ningxia (宁夏) ve Guangxi (广西) gibi önemli azınlık nüfusu içeren beş il özerk azınlık bölgeleri olarak belirlenmiş olmakla beraber; ülke genelinde 31 özerk makam, 96 özerk idari bölge ve sancak, Han egemen illerinin de içinde bulunduğu sayısız özerk köy vardır. Bu bölgeler için öncelikle kaynakların yönetimi, vergiler, doğum planlaması, eğitim, yasa, yargı ve dini ifade üzerinde yerel kontrolün arttırıldığı anlamına gelen "özerk" ifadesi kullanılmaktadır (Gladney, 1994, s. 185).

Azınlıklara yönelik özerkliğin, hükümetin kurallarına biat ettikleri sürece verildiği görülmektedir. Azınlıkların hükümet politikalarına etki etme olasılıkları oldukça düşüktür, çünkü Han çoğunluğu azınlık alanlarda bile neredeyse bütün önemli pozisyonları tutmaktadır. Lin'e göre hala devam eden bu tahakküm egemenliği, sosyal statüsü çoğunluktaki grubun altında kalan azınlık halklarının marjinalleşmesine yol açmaktadır. Örneğin; azınlık liderlerinin terfi ettirilmesi, temsil ettikleri yerel halktan ziyade hükümete hizmet etmek içindir. Han çoğunluğu arasında uzun zamandır varlığını sürdüren "Büyük Han"2 zihniyeti, azınlıklara karşı önyargı ve ayrımcılıklara neden olmaktadır (Lin, 1996). Azınlıklar çoğunlukla iç kesimlerdeki fakir ve az gelişmiş bölgelerde yaşadıkları için ekonomik olarak da ülkedeki fakir grupları oluştururlar. Bu nedenle de Han soyundan gelenler azınlıkları daha ilkel olarak görme eğiliminde olabilmektedirler.

Tarihsel olarak, 1949'dan 1980'lerin başlarına kadar okullar, öğrencilerin kendi özgüllüklerini tanımak, özümsemek, özerklik ve yerel inisiyatifleri desteklemekten ziyade hükümetin merkezi kontrolüne uygunluğu ile yönetilmiştir. 1966-1976 Kültür Devrimi ${ }^{3}$ (无 产阶级文化大革命) sırasında azınlık halkların kültür ve gelenekleri kınanmış, azınlıklar saldırıya maruz kalmışlar; azınlık okulları, yalnızca çoğunluk dili olan Mandarin'i ${ }^{4}$ kullanmak zorunda kalmışlar ve yerel ekonomik gelişme ve eğitim seviyelerine bakılmaksızın tüm ülke için tasarlanmış bir müfredata göre eğitim öğretime zorlanmışlardır. Azınlık öğretmenleri ve öğrencilerinden, standart müfredatı ve soru sormadan öğretim metodunu benimsemeleri beklenmiştir (Lin \& Yanyu, 1996).

\footnotetext{
${ }^{1}$ Han'lar Çin'de yaşayan en büyük etnik gruptur.

${ }^{2}$ Han Hanedanlığı, Çin'in tek bir hükümdar altında birleştirildiği dönem olup, Çin kültürü üzerinde derin etkiler bırakmıştır. "Büyük Han" zihniyetine göre, Çin'de yaşayan pek çok insan bu dönemde kurulan kültürel ve siyasal birliğin tek mirasçılarıdır.

${ }^{3}$ Çin Devrimi'nin ruhunu yeniden canlandırmak için Mao Zedong (毛泽东) tarafından başlatılan harekettir.

${ }^{4}$ Günümüzde standart Çince (putonghua 普通 话) olarak bilinen ve Çin Halk Cumhuriyeti'nin resmi dili olarak kabul edilmiş Pekin lehçesidir.
} 
Kültür Devrimi'nin kargaşası sona erdikten sonra bazı değişiklikler meydana gelmeye başlamıştır. 1978'den bu yana, ülkedeki modernleşme programının benimsenmesiyle birlikte, hükümetin azınlıklara yönelik politikasının da yavaş yavaş değişmeye başladığı görülmüştür. Etnik gerginlik ve ülkenin parçalanma olasılığıyla karşı karşıya kalan Çin hükümeti, azınlıklarla ilişkileri geliştirmek için çeşitli kararlar almıştır. Örneğin, azınlık ailelerin Han çoğunluğu için izin verilmeyen birden fazla çocuğa sahip olmalarına izin verilmiş, yoksul bölgelere özel yardımlar yapılmış ve bu bölgeler devlete vergi ödemekten muaf tutulmuştur (Tawakkul, 1999, s. 72-80).

Azınlık dili ve kültürünün canlandırılması da Kültür Devrimi'nden sonra alınan en önemli kararlardan birisi olmuştur. 1980'lerden başlayarak, azınlık çocuklarına yönelik eğitim olanaklarının arttırılması için çaba gösterilmiştir. Örneğin, üniversitelere giriş için kabul standardı düşürülmüş, uzak ve fakir azınlık bölgelerinde yaşayan öğrenciler için yatılı okullar açılmış, ayrıca azınlık bölgelerinde çalışan öğretmenler için maaşlar arttırılmıştır ancak bu ılımlı girişimler, azınlıkların yüksekokulları bırakma oranlarını düşürmek için yeterli görülmemiştir (Chen, 1996, s. 40-47). Buradan Mandarin dilindeki eğitimin azınlık çocuklar için, özellikle de bu dille daha önce hiç tanışmamış olanlar için, çok zor olduğu açıkça görülmektedir. Bu nedenle de iki dilli eğitim, azınlık öğrencilerinde öğrenmenin iyileştirilmesi için okullaşmanın önemli bir bileşeni olarak görülebilmektedir.

\section{Bilim İnsanlarının İki Dilli Eğitim Parametreleri ve Hükümetin Tutumu}

Çin'deki bilim insanlarının, özellikle bilişsel nedenlerle azınlık öğrencilerine iki dilli eğitim sağlamayı savundukları düşünülmektedir. Bu anlamda azınlık öğrencileri, özellikle de Han kültürüyle çok az teması olan ve sadece kendi ana dillerini konuşup uzak bölgelerde yaşayanlar için, zihinsel yeteneklerinin geliştirilmesi açısından iki dili eğitim-öğretimin zorunlu olması gerekliliği savunulmuştur. Binlerce yıldan beri sürekli olarak gelişen ve değişen Han dili, bu öğrenciler için çok zordur. Onları yalnızca Mandarin dilinde ders veren bir sınıfa sokmak, onların cesaretlerini kırabilmektedir. Bu nedenle, bilim insanları iki dilli eğitimin okul ile ev arasında bir köprü kurmaya yardımcı olacağını, öğrencilerin ilgisini çekeceğini ve onlara özgüven ve saygı duygusu geliştirmelerinde yardımcı olacağını savunmuşlardır (Liu, 1993, s. 8-75). Hükümet adına iki dillilik üzerine araştırma yapan bilim insanları verdikleri raporlarda, kendi dillerinde öğrenmenin birinci sınıfta başlaması gerektiğini belirtirken; Mandarin'in de ortaokulda eğitim ve öğretimin ana dili haline gelinceye kadar kademeli olarak tanıtılması fikrini ileri sürmüşlerdir (Shama, 1991, s. 7-55). $\mathrm{Bu}$ fikir, öğrencilerin daha geniş bir toplum içinde işlev görmelerini sağlayıp, böylece istihdam olanaklarını arttırarak çeşitli kültürel değiş tokuşları kolaylaştırabilecektir.

1966-1976 yıllarındaki Kültür Devrimi'nden sonraki sosyal, siyasi, ekonomik alandaki yenileşme kararları incelendiğinde hükümetin, azınlık kültürünün korunması ve teşviki için iki dilli eğitime daha 1 lımlı baktığı bu alanda yapılan reform girişimlerinden anlaşılabilmektedir. Bu amaçla hükümetin gerekli politikaları formüle ederken, dilin önemli kültürel bilgiler taşıdığını da kabul ettiğini söyleyebiliriz. Kendi dillerini bilmek sadece öğrencilerin değil tüm insanların kültürel değerlerini ve inançlarını öğrenip devralmalarına yardımcı olabilmektedir.

Azınlıklar için iki dilli eğitim hem bilim insanlarından hem de merkezi hükümetten destek almıştır. 1985 itibariyle hali hazırda 160.000 okul ülke çapında yaklaşık 2,5 milyon öğrenciye iki dilli eğitim olanakları sunmuştur. Bunun yanı sıra 1990'larda bazı bölgelerde ise çalışmaların sekteye uğradığı ve bazı azınlık bölgelerinde ders kitapları, öğretmenler ve SEFAD, 2021; (45): 49-62 
yerel destek yetersizliği nedeniyle bu politikadan vazgeçildiği konusu da haberler arasında yer almıştır. Bununla birlikte, 1995 yılında içlerinde Moğollar, Tibetler, Koreliler, Uygurlar ve Zhuangların (壮族) da olduğu 23 azınlık grubu kendi dillerini ya da hem kendi hem de Mandarin dilini eğitim öğretim için kullanmışlardır. Sekiz il azınlık okullarına ders kitapları sağlayabilmek için kendi yayınevlerini kurmuşlardır (People's Daily, 21 Ekim 1995, s. 3).

Çin Halk Cumhuriyeti 2000'li yılların başında eğitim politikalarında, özellikle de etnik grupların çoğunlukta olduğu Sincan (Xinjiang/新疆) ve Tibet (Xizang/西藏) otonom bölgelerinde yenilikler yapmıştır. Örneğin; 7 Temmuz 2002 tarihinde “Danıştay, Reformu Derinleştirme ve Etnik Eğitimin Gelişimini Hızlandırma Kararı (国务院关于深化改革加快发 展民族教育的决定)" yayımlanmıştır. Bahsi geçen kararın 6. maddesinde iki dillilik eğitim politikasından şu şekilde bahsedilmektedir:

\begin{abstract}
“Öğretmen kadrosu şiddetle güçlendirilmelidir. Öğretmen kadrosunun oluşturulması, milli eğitimin gelişiminin odak noktası olmalı ve eğitim yattrmmları, öğretmen kadrosunun inşasının ihtiyaçların sağlar nitelikte olmalıdır. Etnik azınlklardan ve batı bölgelerinden oluşan öğretmen ekibinin inşasıyla, "iki dilli" öğretmenleri eğgitmeye odaklanılmalı ve nitelikli bir "iki dilli" öğretmen ekibi oluşturulmaldır. Öğretmen eğitim sistemi reformu daha da derinleştirilmeli, normal kolejlerdeki öğretmenlerin öğretim ve araştırma seviyeleri iyileştirilmeli ve il düzeyinde öğretmen yetiştirme üsleri inşa edilmelidir. Aynı zamanda, sürekli eğitimin kalite ve etkisini arttırmak için uzaktan eğitim gibi modern yöntemler de kullanılmalıdır. Etnik bölgelerdeki okul müdürlerinin eğitimleri de güçlendirilerek, okullarm yönetim düzeyi iyileştirilmelidir. Öğretmenlerin kaynakları genişletilmeli, doğu ve orta bölgelerdeki kolej ve üniversitelerin mezunlar etnik azınlılarda ve batı bölgelerinde ders vermeye teşvik edilmelidir. Tarımsal ve krrsal alanlarda, dağllk alanlar ve sinır bölgelerde her düzey ve türde öğretmenlerin eğitimini güçlendirmek için özel önlemler alınmalıdır. Öğretmenlerin eğitimini güçlendirin, onlar çeşitli iş araştırmalarna katılmaya teşvik ederek, akademik olarak da niteliklerini geliştirin. Öğretmenlere saygı duyma ve tüm toplumda eğitime değer verme konusunda iyi bir ahlak oluşturmak için öğretmenlerin ücretlerini ciddiyetle garanti altına almak ve sürekli iyileştirmek gereklidir (The State Council The People's Republic of China, 7 Temmuz 2002 )."
\end{abstract}

Çin resmi olarak 2010 yılında tüm azınlık bölgelerindeki okullar için "iki dilli eğitim" politikası getirmiştir. Azınlık eğitimine yönelik bu yaklaşım, hem yerel hem de ulusal dilde yeterliliği teşvik ettiğinden uluslararası olarak uygun kabul edilmiştir. Çin'in 2010-2020 orta ve uzun vadeli eğitim reformu ve ulusal kalkınma planının özetinde stratejik hedefler, temalar, misyonların yanı sıra öğretmenlerden, okul ve öğrencilere kadar pek çok konunun üzerinde durulmuştur (Wang \& Phillion, 2009, s. 1-14). Bu konulara çalışmanın alt başlıklarında detaylı olarak yer verilmiştir.

\title{
2. İki Dilli Eğitimin Uygulama Politikaları ve Sorunları
}

Çin Halk Cumhuriyeti Anayasası'nda, “her milletin kendi dilini kullanma ve geliştirme özgürlügüne sahip olduğu" görüşü 1950'lerde yer etmiş ve 1980'lerde revize edilmiştir (The State Council The People's Republic of China, 4 Aralık 1982). Yasanın yürürlüğe girmesinin yanı sıra, belirlenmiş 5 azınlık özerk bölgesi, azınlık kültürü ve eğitiminin gelişimini denetlemek için ayrı ayrı veya azınlık meseleleri komiteleriyle birlikte çalışan azınlık dil komitelerini kurmuştur. Bu bölgelerdeki il eğitim büroları içinde, azınlık okullarında iki dilli eğitimin uygulanması da dâhil olmak üzere azınlık eğitiminin gelişimini 
denetlemek amacıyla bir azınlık eğitim işleri ofisi bulunmaktadır. 1950'lerde hükümet inisiyatifleri altında, tarihsel nedenlerden ötürü yazma sistemi olmayan bazı azınlık gruplarına yeni yazma sistemleri oluşturmak için bilim insanları bir araya gelmişlerdir. Toplamda 32 yazılı dil oluşturularak, bunlardan bazıları okullarda kullanılmak üzere kabul edilmiştir (Zhou, 2003, s. 89).

Azınlık dillerine kanunen Han dili ile eşit statü verilmesine rağmen, tarihsel koşullar politik ve ekonomik kalkınmada çeşitli azınlık dillerinin işlevleri ve erişilebilirliği üzerinde etkisi olan eşitsizlikler yaratmıştır. İlk olarak, Mandarin tüm devlet kurumlarında ve medyada konuşulan resmi dil olmaya devam etmiştir. İkincisi, toplumda ödül mekanizmaları Han çoğunluğu tarafından ve Han soyundan olanlar için kurulmuştur. Han dili, fırsatların ve sosyal kabulün merkezi iken, azınlık dilleri kullanımda ve sosyal statüde kısıtlı kalmıştır. Azınlık alanlarındakiler de dâhil olmak üzere hem ilköğretim hem de orta öğretim okullarında, çoğu talimat Mandarin dilinde verilmiştir. Ulusal kolej ve üniversite giriş sınavı dâhil tüm giriş sınavları Han dilinde yapılmaktadır. Son yıllarda azınlık öğrencilerinin üniversite giriş sınavına kendi dillerinde girebilmeleri için bazı şartlar eklenmiş, ancak bu fikir en büyük azınlık nüfusa sahip il olan Guangxi'de (广西) bile hiçbir zaman uygulanmamıştır (Stites, 1992). Bu koşulların aslında iki dilli eğitimi marjinalleştirerek, uygulanmasında büyük engeller yarattığı düşünülebilir.

Bunlara ek olarak, azınlıkların statüsünün düşük olması, çok sayıda yerel yönetim görevlisinin azınlık dil öğrenimini gereksiz bulmalarına neden olmuştur. Dikkate değer bir örnek verecek olursak Zhuang dili, 1957 yılında Zhuang azınlık grubu için oluşturulmuş ancak Kültür Devrimi'nin sonunda da kullanılmayan bir dil haline gelmiştir (Zhou, 2003, s. 58-59). 1980'lerde il yönetimi, azınlık okullarında dilin yaygın olarak kullanılmasını teşvik etmek için çeşitli düzenlemeler yapmıştır ancak bu girişim büyük bir karşı dirençle karşılaşmıştır. Örneğin, Guangxi'nin kuzey merkezindeki Zhuang kadrolarında çalışanlar, çocuklarının ne Zhuang dilini ne de Guilin (桂 林) lehçesini öğrenmelerine izin vermeyeceklerini, Han lehçesinin ortak yerel lehçe olduğunu belirtmişlerdir. Çocuklarının sadece standart Mandarin'i öğrenmelerini istemişlerdir. Bunun gibi birçok bölgede azınlık dilinin toplumsal öneminin olmaması, azınlık dillerinin gelişimini ve iki dilli eğitimin uygulanmasını olumsuz etkilemiştir (Stites, 1992, s. 18). Bu insanlar, çocukları Han dilini en başta öğrenemez ve sosyal statülerinin yükselmesi şansı azalacak olursa diye duydukları endişelerinden dolayı suçlanamazlar.

Azınlık okullarında iki dilli eğitim politikası ile hükümetin Mandarin'i ülkenin ortak dili olarak tanıma politikası doğrudan çelişkilidir. Bu konuda Stites düşüncelerini şu şekilde ifade etmektedir:

\footnotetext{
"Çin partisinin/ devletinin, azınlık dilinin statüsü konusundaki temel konumu bariz çelişkilidir. 1949'dan itibaren, Çin Anayasası'nın 53. maddesine göre, bütün milletlerin kendi dillerini ve yazı sistemlerini geliştirme ve kullanma hakkı vardır. Mevcut anayasa öncekiler gibi Putonghua'nın (普通话/ Mandarin) tanıtımı ve genel kullanımı için de bir hüküm içermektedir. Bu hükmün 1982 versiyonunu öncekilerden ayıran, Putonghua'nın tüm Çin vatandaşları tarafından kullanılması gerektiği yönünde açık bir ifadedir. Bu iki anayasa hükmü, Çin'in toplumsal iki dillilik konusundaki resmi duruşunun yasal ve ideolojik bağlamın sağlamaktadır. Ayrıca, Çin'in iki dilli eğitim politikalarının formüle edildiği ve yorumlandiğı alanın sınırlarını da çerçevelemektedir (1992, s. 4)."
}

SEFAD, 2021; (45): 49-62 
Diğer bir ikilem ise, iki dilli eğitimin yalnızca ilköğretim okullarında benimsenmesi ve öğrencilerin bir kez ortaokul ve üniversitelere girdikten sonra kendi dillerinde öğrenimlerinin durdurulması konusudur. Bu süreksizlik azınlık öğrencilerinin her iki dilinin de zayıf ve eksik olmasına neden olabildiği gibi; üniversite düzeyindeki azınlık öğrencileri, çalışmalarına çok az destekle, kendi dil ve kültürlerinin değerinin farkında olmadan devam edebilmektedirler. Heath, Çin'deki bir üniversitede ders verirken, bu sebeplerden dolayı birçok azınlık öğrencisinin Han öğrencilerinin gerisinde kaldığını gözlemlemiştir. Ona göre öğrenciler aksanlarını gizlemek için büyük acılar çekiyorlar ve küçük görülebileceklerini düşündükleri için etnik kıyafetlerini giymeyi reddediyorlardır. Açıcçası, iki dilli eğitim ile ilgili konular hiçbir zaman tamamen dilbilimsel değildir, ama her zaman güçlü bir biçimde sosyal ve politiktir (1981, s. 6-20).

\section{Okullarda İki Dilli Eğitim Uygulamaları}

\subsection{Merkezileştirilmiş Müfredat}

Çin de birçok ülkede olduğu gibi Eğitim Bakanlığı tarafından takip edilecek tüm okullar için tasarlanmış merkezi bir müfredata sahiptir. Azınlık bölgelerinde yaşayan öğrenciler, diğerleriyle aynı ders kitaplarını kullanırlar ve aynı hızda ilerleme göstermeleri beklenir. Bu yaklaşım yukarıdan aşağıya hükümetin eğitimdeki kontrol mekanizmasını karakterize etmektedir. Bu müfredatta konu alanları muhtemelen önceden belirlenmiş olup, yerel okullara az esneklik bırakılmıştır. Ebeveynler ve yerel yönetimler, ne öğretilmesi gerektiği ve öğretimin nasıl gerçekleştiği konusunda ise sınırlı bir söz hakkına sahiptirler.

Müfredat öğrenciler için çok zor ve yerel ihtiyaçları karşılamak için yetersiz görülmektedir. Örneğin, ortaöğretim seviyesindeki Çince ders kitapları, öğrencilerin yaşamlarından ve günlük olarak kullandıkları dilden uzak olan Han klasik kanunları ile doludur. Öğrencilerin içeriği kavramak için çoğu zaman ikili çeviri yapmaları gerekmektedir. Buna ek olarak çalı̧̧malarının sonunda da azınlık öğrencilerinin kolejlere ve üniversitelere kabul için eşit derecede Han öğrencileriyle rekabet etmeleri gerekmektedir. Sonuç olarak, azınlık öğrencilerinin her tür ortaöğretim sonrası ve yükseköğrenim kurumundaki sayıca oranları, Han çoğunluğu öğrencilerinin sayıca oranlarından daha düşük olmaktadır (Cleghorn, 1989, s. 21).

\subsection{Ders Kitabı Derleme ve Yayınlama}

İki dilli eğitimin sağlanmasında ders kitabı yayınlanması ve eğitimi en önemli konulardan biridir. 1980'lerin başında azınlık öğrencilerine yönelik ders kitaplarının derlenmesi için yoğun çaba harcanmıştır. 1991 yılına kadar 24 azınlık gruptan 30 dilde çeviri ve yayın 1800 'e ulaşmış ve toplamda 80 milyon cilt basılmıştır (Lin, 1997, s. 193-205). Bununla birlikte, birçok okulda sadece ulusal ders kitabı çevirileri veya azınlık dili karakter çizgileri bulunmaktadır. Öğretmen ve öğrencilerin Mandarin dili dışında referans kitapları ya da ek okuma materyalleri mevcut değildir. İki dilli eğitimi daha iyi uygulamak için, 100 'den fazla dilde ders kitabına ihtiyaç vardır ancak baskı hacmi çoğu için birkaç düzine ve cilde kadardır. Yapılan tercümelerden sonra, metinlerin genellikle \%50 daha uzun olması baskı maliyetini arttırabilir fakat satış fiyatının ulusal müfredat için olan fiyattan daha yüksek olmasına izin verilmemektedir. Bu nedenle, matbaalar da normal şekilde çalışamamaktadır. Birçok yayıncı, yeterlilikten uzak devlet yardımlarına güvenmek zorunda kalabilirler. Az sayıda yayınevi, hayatta kalıp gelir elde etmek için okullarla ilgili olmayan romanlar ve kitaplar yayınlamak zorunda kalmaktadırlar. Çünkü; iki dilli kitaplar yayınlamak para kaybedilen bir iş olarak nitelendirilmektedir. Sonuç olarak azınlık kitapları 
eğitim sürecini olumsuz yönde etkileyerek iptal edilir ya da ertelenir. Örneğin, 1985 yılında Yi dilinde ders kitaplarının basımı 3 ay boyunca ertelenmiş, 1574 öğrencisi olan 39 sınıf yarıyıl boyunca Han ilkokuluna geçmek zorunda kalmışlardır (Shama, 1991, s. 7-55).

\subsection{Eğitim ve Öğretim}

Zhou Qingsheng, daha önceki çalışmaların eleştirel bir analizine ve yurtdışında yapılan araştırmaları uyarlamaya dayanarak Çin'deki iki dilli eğitim uygulamalarını kategorize etmek için iki model geliştirmiştir. Bu iki model şunlardır:

Model 1 İki dilli eğitim sistemi: Ĕgitimin iki dilde yapıldı̆̆ı modeldir. Bu modelde öğretmenler Mandarin dilinde eğitim verir ve azınlık dilini açıklama yapmak için kullanırlar. Mandarin kullanılan ana dildir ve azınlık dili yalnızca Han Mandarin dilini daha iyi öğrenmeyi kolaylaştırmak için kullanılmaktadır.

Model 2 İki dilli müfredat: Öğrencilere öncelikle azınlık dilinde eğitim uygulanır; Han Mandarini öğrenciler kendi azınlı dillerinde uzman oldukları zaman öğretilmeye başlanır. Bu modelde amaç, sonunda öğrencilerin her iki dilde de akıcı ve uzman olmalarını sağlamaktır (1991, s. 65-69).

Kısmen bütünleştirici bir yaklaşım benimseyen ilk model, azınlık dili öğrencilerinin eğitiminde çoğu okul tarafından uygulanan bir modeldir. İkinci model ise genellikle azınlık öğrencileri için eğitime değer veren yerel okullar tarafından benimsenen bir modeldir (Zhou, 1991, s. 69).

Temel olarak, ilk model azınlık öğrencilerinin baskın kültürün bir parçası olmalarına yardımcı olmaya odaklanmaktadır. Bu modelde asimilasyon nihai amaçtır. Genel olarak azınlık öğrencilerinin eğitimde uygun materyallere sahip olmadıkları görülmekte ve bu nedenle iki dilli eğitimin öğrencilerin Han dilinde ders kitaplarını öğrenmelerini kolaylaştırması beklenmektedir (Blachford, 1997, s. 160). Azınlık dillerinde eğitim yalnızca Han dilinin öğrenilmesi demektir. Bu nedenle, birçok azınlık okulu ulusal müfredata odaklanmaktadır; bunun sonucu olarak da, iki dilli eğitimin azınlık dili için bir okumayazma kitabı veya azınlık dilinden karakterleri içeren bir poster niteliğinde olması azaltılmıştır. Bu bağlamda, çok sayıda azınlık ilköğretim okulu, Han dilinin öğretilmesine ayrılan zamana oranla azınlık dilinin öğretilmesine daha az zaman ayırmaktadırlar ( $\mathrm{Wu}$, 1989, s. 69).

Genel olarak, iki dilli eğitimin, azınlık öğrencilerine Han dilini öğrenmelerinde adeta bir "koltuk değneği" sağlamak için var olduğu inancı eğitim ve öğretime zarar vermektedir (Wu, 1989, s. 69). Kendi dillerinde eğitim göremeyen bu öğrenciler, öğrenmeye ilgi duymaları ve zekâlarını geliştirmeleri için yaşamlarındaki en kritik aşamayı kaçırmış olurlar. Örneğin, Yunnan'daki (云南) bir Dai (傣族) azınlık bölgesinde, öğrencilerin çoğu Han dilini öğrenmenin onlar için çok zor olduğunu belirterek, beşinci sınıfa gelmeden önce okulu bırakmışlardır. Kendi sözleriyle ifade edecek olursak: "Sınıflar genellikle birinci ve ikinci sınıflarda doludur, ancak yalnızca birkaç öğrenci üçüncü ve dördüncü sınıfta kalır, beşinci ve altıncı sınıfta neredeyse tüm öğrenciler okulu terk ederler (Wu, 1989, s. 70)." Ortaokul seviyesine gelenlerin çoğu ise hala Han dilinde bir cümle kuramayacak kadar vasattırlar. Nitekim bu aşamada öğrenim oldukça azdır, çünkü testler en iyi azınlık öğrencilerinin 100 üzerinden 30 ila 40 puan, ortalama öğrencilerin 10 ila 20 puan, vasat öğrencilerin ise sadece birkaç puan alabildiklerini göstermiştir. Han dilinde öğrenme zorluğundan tamamen

SEFAD, 2021; (45): 49-62 
vazgeçen öğrenciler, tapınakları yerel okullara tercih ederler ve usta keşişlerden daha fazla şey öğrenerek keşiş olurlar (Wu, 1989, s. 70).

Örneklendirdiğimiz tüm bu olumsuz sonuçlar, azınlık dillerinde öğretimin erken yaşlarda uygulanması çağrılarına neden olabilmektedir. Bununla birlikte, öğrencilerin kendi dillerinde eğitim almalarını sağlamak ve ayrıca Han dilini kademeli olarak öğrenmek de önemli bir konu haline gelmektedir. Model 2'yi benimsediklerini bildiren bir okul Bai (白族) öğrencilerine eğitim vermede şu şekilde bir sistem geliştirmiştir: Bai dili (白语) öğretimde birinci, Han dili ikinci sıradadır; böylece Han dilini öğrenmek için Bai dilini kullanmak ve öğrencilerin her iki dilde de akıcı olmalarını sağlamak hedeflenmiştir. Bu sistem okula başlamadan önce tam anlamıyla Han dilini bilmeyen Bai çocukları için tasarlanmıştır. Okul, anaokulunda ve birinci sınıfta öğrencilere \%100 Bai dilinde eğitim verir, ikinci yıl boyunca öğrenciler zamanın \%75'ini Bai dilinde \%25'ini Han dilinde eğitime harcarlar. Böylece Han dilinin öğrenme yüzdesi öğrenciler yüksek notlar aldıkça artarken, Bai dilininki ters orantılı olarak azalır. Bu yaklaşımı kullanan öğretmenler, akademik öğrenmeyi de oldukça iyi seviyelere taşımışlardır. Öğretmenler, ikinci bir dile geçmeden önce öğrencilerin bir dili kullanmaları konusunda rahat olmaları için yeterli zamanın tanınması gerektiğini ve onların eğitim sürecinde iki dil arasında ayrım yapmalarına yardımcı olmaları gerektiğini vurgulamaktadırlar (Yang \& Xi, 1995, s. 58-62).

Etkili bir şekilde yapılan eğitim, öğretmenin mevcut dil iletişimi ve kültürel anlayış engellerini aşmasını gerektirmektedir. Bu anlamda Han dilinin büyük bir kelime hazinesi olup, karakterlerin çoğunun birçok anlamı vardır ve bunların karmaşık şekillerde ortaya çıkabildikleri görülmektedir. Ayrıca metinlerdeki bazı cümlelerin anlaşılması, Han kültürü ve tarihi ile ilgili bir bilgiyi de gerektirmektedir. İkinci dil öğreniminde öğretmenlerin iki dil arasında bağlantılar kurmaları eğitimi çok daha kolay bir hale getirebilmektedir. Bu bağlantıların kurulabilmesi ise belirli bir azınlık grubunun tarihine ve yaşam ortamlarına da aşina olmayı gerektirebilmektedir. Örneğin, Batı Çin'in Sincan eyaletindeki bir öğretmen, Uygurların sürülerinin hayatlarında geliştirdikleri deneyimleri kullanarak, öğrencilerin müfredatı anlamalarını kolaylaştırabildiğini şu ifadelerle bildirmiştir:

\footnotetext{
"Bir millet için, günlük yaşamları kültürlerinin özünü yansıtır. Sı̆̆ırlar Uygurların ekonomik yaşamlarında çok önemli bir yere sahiplerdir ve bu nedenle "at, inek ve koyun" sıklıkla zengin anlamlar taşıyan metaforlar oluşturmak için kullanılır. Örneğin, "iyi atın da kötü huylu olabileceği" ifadesi, itaatkâr bir kişinin de bazen meydan okuyabileceğini ifade etmektedir (Zhang, 1992, s. 66)."
}

Buna göre, eğitimde etkili olmak adına öğretmenlerin diller arasındaki anlayış boşluklarını gidermede metafor ve örneklemeleri kullanmaları, ayrıca öğrencilere her dilin kullanımını uygulamada fırsatlar sunmaları gerekli görülebilmektedir.

Genellikle öğretmenlerin ders verdiği ve öğrencilerin dinlediği çoğu Çin sınıfında geleneksel eğitim yöntemleri uygulanmaktadır. İki dilli bir sınıfta ise öğrencilerin öğrenme sürecinde katılımcı olabilmeleri için yeni yollar bulunmalıdır. Araştırmacılar, öğrencilere fikirlerini paylaşma ve örnekler sunma fırsatı verildiğinde eğitim ve öğretimin çok daha etkili bir şekilde gerçekleştiğini ileri sürmektedirler (Wang, 1995, s. 6-75). Bununla birlikte, öğrenme alışkanlıkları tartışma ve katılımlarla desteklenmelidir. Öğretmenler öğrenciler arasındaki farklı öğrenme hızlarına saygılı olmalıdırlar. Han dilini kabul etmeleri için hiçbir güç uygulanmamalıdır, çünkü eğitim dışsal zorlamalardan değil, gerçek ilgiden gelir (He, 1995, s. 9-77). 
Çin'in 2010-2020 orta ve uzun vadeli eğitim reformu ve ulusal kalkınma planının özetinde, etnik azınlıklar için eğitim kalitesinin yükseltilmesi konusunda; iki dilli eğitimi ilerletmek, her okulda Çince dersleri açmak ve ulusal ortak dil ve yazı sistemini yaygınlaştırmak için hiçbir çabadan kaçınılmayacağı belirtilmiştir. Bunun yanı sıra azınlık halklarının ana dillerinde eğitim alma hakkına saygı duyulup bu ortamın yaratılacağı da duyurulmuştur. Özellikle iki dilli okul öncesi eğitimin yaygınlaştırılması konusu üzerinde durularak; öğretmen yetiştirme, öğretim teknikleri araştırma ve ders kitaplarının derlenip yayınlanması için devlet desteği verileceği belirtilmiştir (Outline of China's National Plan for Medium and Long-term Education Reform and Development, 9 Temmuz 2010, s. 23).

\section{4. Öğretmenler ve Öğretmenlerin Eğitimi}

Çin'deki azınlık okulları nitelikli öğretmenlerin eksikliğinden muzdariptir. Kısıtlı ulaşım, bilgi eksikliği, yoksulluk, düşük gelir seviyesi ve azınlıkların düşük sosyal statüsü kalifiye öğretmenlerin girişim ve gelişimlerini de kısıtlayabilmektedir. Öyle ki bu konuda geçtiğimiz yirmi yıl boyunca, öğretmenlik kolejlerinden mezun olanların azınlık bölgelerinde çalışmaya teşvik edilmesi için çeşitli kararlar alınmıştır. Örneğin, azınlık bölgelerde çalışanların bir deneme süreleri olmaz, çalışma ve yaşam koşullarının iyileştirilmesi ön planda tutulur ve ulusal ortalamanın üzerinde ücret alırlar. Diğer bir avantajları ise ikinci bir çocuğa sahip olmalarına izin verilmesidir. Ayrıca il hükümetleri, kabul standartlarını düşürerek öğrencileri azınlık alanlarından çekecek öğretmen yetiştirme kurumları kurmuştur. Bu öğrenciler 2 ila 3 yıllık bir eğitimin ardından köylerine dönerek öğretmenlik yapabilmektedirler. Alınan bu kararlar, öğretmen eksikliğinin ciddi durumunu hafifletmeye yardımcı olmaktadır (Chen, 1995, s. 7- 56).

Koordineli bir öğretmen yetiştirme sistemi bulunan alanlarda başarılı iki dilli eğitim programları rapor edilmiştir. Bu alanlarda öğretmenlere hizmet içi eğitim, hizmet öncesi eğitim ve özel eğitim programları sağlanarak iki dilli eğitim gerçekleştirme becerilerinde destek sağlanmıştır. Bazı okullar, iki dilli eğitim sınıfları kurarak, öğretmenlere belirli azınlık dillerini öğretebilmek için bütçe temin etmiş̧lerdir. Örneğin, 1993 yılında güneybatı Guizhou (贵州) eyaletindeki Bijie (毕节) ilinde, 48 iki dilli eğitim bölgesi kurulmuş ve Yi (彝族) ve Miao (苗族) azınlık dillerinde ders vermek için eğitilecek 20 öğrenci alınmıştır (Chen, 1995, s. 7-56).

$\mathrm{Bu}$ gelişmelerin genel anlamda dengesiz şekilde gerçekleştiği görülmektedir. Öğretime erken yaşlarda başlayan ve iki dilli eğitimin ilköğretimden yükseköğrenime kadar gerekli altyapısını oluşturan azınlık alanlarının diğerlerinin ötesine geçtikleri gözlenmiştir. Örneğin Koreliler bunu başarabilmişlerdir. Kuzeydoğu Jilin (吉林) eyaletindeki Yanbian (延 边) ilinde, Koreli öğrenciler için ilk dili Korece öğreten tam anlamıla entegre programlar bulunmaktadır. Onlar öğretmenlerin eğitimi, ders kitabı derleme ve yayınlama ile eğitimde destek ve araştırmaları başarmışlardır. Politikalarda tutarlılığı ve finansmandaki sürekliliği korumuşlardır. Öğretmenleri iki dilli sınıflarda ders vermek için hizmet öncesi, hizmet içi ve bireysel eğitim alma fırsatlarına sahiplerdir. Sonuç olarak, Koreliler genel olarak Han çoğunluğunun düzeylerini aşarak, eğitimde en yüksek başarıya sahip olabilmişlerdir. Örneğin, 1990 yılında ilkokul düzeyinde kayıt oranları, okulda kalma oranları ve yükselme oranları sırasıyla \%98.8, \%98.6, \%98.1 şeklinde olmuştur (People's Government of Yanbian Prefecture of Jilin Province, 1992, s. 3/ 8-96). Son yıllarda Kore dilinde öğretmenlik, Çin'in Güney Kore ile ekonomik ilişkiler kurması ve daha fazla iş imkânı sağlaması ile daha da

SEFAD, 2021; (45): 49-62 
güçlenmiştir. Raporlara göre, ebeveynler çocuklarını iki dilli okullara özellikle Korece öğrenmeleri için ciddi şekilde göndermektedirler (Guan, 1995, s. 15- 20).

Buna karşılık, bazı yerlerde ise iki dilli eğitim yeni yeni gelişmektedir. Yunnan, Guangxi, Guizhou ve Tibet gibi yerlerde, iki dilli eğitimi normal eğitim faaliyetlerine entegre etmek için uzun yıllar gerekmektedir. Öğretmenlerin ve tesislerin yetersizliğine ek olarak bu yerlerde iki dilli eğitimin önemi konusunda da düşük bir farkındalık vardır (Zhou, 1991, s. 69 ).

Yine 2010-2020 kalkınma planının özetine göre öğretmenlerin profesyonel verimliliğini artırma konusunda da yeniliklere gidilmiştir. Bu plana göre; normal üniversite öğrencileri için ücretsiz eğitim geliştirilecektir. Öğretmenleri zorunlu eğitim veren kırsal alandaki okullara çekmek için özel öğretmen kadroları kurma planı daha güçlü bir şekilde uygulanacaktır. Üniversite mezunlarını uzak bölgelerde ders vermeye teşvik etmek için uygulanabilir tazminat mekanizmaları onaylanacaktır. Öğretmenlerin eğitim sistemi, hükümet bütçelerinde taahhüt edilen finansmanla iyileştirilecektir. Tüm öğretmenler her beş yılda bir güncel konulardan yeniden eğitim alacaklardır. Azınlıkların yaşadığı bölgelerde iki dilli öğretmen eğitimi güçlendirilecektir. Öğretmenlerin yanı sıra okul müdürleri de eğitilecek ve sınıf danışmanlarına da aynı özen gösterilecektir. Normal üniversitelerin en önemli rolü oynadığı öğretmen eğitimi reformu, özel üniversitelerin de dâhil olabileceği açık ve esnek bir eğitim sistemi inşa etmek için derinleştirilecektir. Tüm bunlar vasıtasıyla genel eğitim kalitesinin geliştirileceği belirtilmiştir (Outline of China's National Plan for Medium and Long-term Education Reform and Development, 9 Temmuz 2010, s. 37).

\section{SONUÇ}

Her ne kadar Çin'de iki dilli eğitim azınlık öğrencilerinin eğitim seviyelerini yükseltmek için teşvik edilmiş olsa da bir diğer açıdan bakıldığında asimilasyonlarını kolaylaştırmak için de kullanılabilmektedir. İki dilli eğitim hakkında öğrencilerin daha etkili öğrenmelerine yardımcı olacak ümit verici raporlar da olmuştur; ancak azınlıklar için eğitimin gelişimi ile ilgili sorunların dil konusunun çok ötesine geçtiği de bir gerçektir. Çin'deki pek çok azınlık okulunda sadece kilden yapılmış masalar vardır ve kitap, sandalye, deney yapma ekipmanları ve spor tesisleri mevcut değildir. Bu nedenle bazı okullar, sınıf yetersizliğinden dolayı alacakları öğrencilere resmen bir piyango gibi çekilişle karar vermek zorunda kalabilirler.

İçinde bulunduğumuz teknoloji çağında bu gibi durumlarla karşılaşmamak adına azınlık öğrencilerinin eğitim ve öğretimlerini kolaylaştırmak için büyük çaba ve girişimler gerekmektedir. Bu anlamda iki dilli eğitimi sadece tanıtmak yeterlilikten uzaktır. Azınlık öğrencileri için eğitimin iyileştirilmesi yolunda diğer sorunların da birlikte ele alınması gerekmektedir. Yani iki dilli eğitimin yanı sıra, mesleki eğitim, teknik eğitim ve benzeri eğitim alanları da mevcut olmalıdır ki böylece öğrenciler okuldaki teorik becerileri pratiğe dökebilmeli, kişisel gelişimlerini tamamlayabilmelidirler.

Çin'de iki dilli eğitimin, kısmen azınlık kültürünün ve dilinin önemini kurumsallaştırmak için tasarlanmış olduğu düşünülebilir. Çünkü baskın kültürün öğrencilerinin azınlık kültürü hakkında bilgi edinmek için uğraşmak zorunda olmamaları, ülke genelinde saygı ve kültürel anlayışı teşvik etmek için oluşturulan iki dilli eğitimin de değerini büyük ölçüde düşürebilmektedir. Bu açıdan bakıldığında iki dilli eğitimi 
uygulamak, fon sağlama ve nitelikli öğretmen yetiştirmeye çalışan iki dilli okulların yükünü ikiye katlayabilmektedir.

İki dilli eğitim programlarının uygulanmasında düzeyli ve istikrarlı politikalara ihtiyaç vardır ancak maalesef ki azınlık bölgelerinin tümü aynı koşullara sahip değildir. Örneğin, Çin'in kuzeyindeki Moğollar, Uygurlar, Koreliler ve Tibetliler gibi birçok azınlık nüfusun tek bir homojen ortamda birlikte yaşadıkları bilinmektedir. Aksine güneydeki birçok azınlık ise Han çoğunluğu ile iç içe yaşamakta, dolayısıyla da onlarla ortak bir dili ve kültürü paylaşmaktadırlar. Bu nedenle, hem Mandarin hem de azınlık dilinin öğretiminin birlikte yaşama alanlarında oluşması muhtemel olabilmektedir.

Diğer bir ihtiyaç ise, iki dilli eğitimin hem politik hem de daha geniş kültürel, ekonomik ve sosyal işlevlerinin anlaşılması konusudur. Azınlık dilinin ve kültürünün korunması ancak azınlık grupların bu tür eğitime duyulan ihtiyacı gördükleri takdirde gerçekleşebilmektedir. Bazı metotların denendiği iki dilli eğitimdeki başarısızlıkların kökleri, sadece okul düzeylerinde değil aynı zamanda toplumsal düzeyde de mevcuttur. Yani azınlıklara kendilerini güçlenmiş hissetmeleri ve koşullarını değerlendirerek çocukları için ne istediklerine karar verme yetkisi tanınabilmelidir; çünkü bu özerklik olmadan, özgüven oluşturmanın ve eğitimin uygunluğunu gerçekleştirmenin gerekli şartları sağlanamayabilir.

Son olarak, toplumun yapısında da değişikliklerin olması gerekmektedir. Burada kastettiğimiz şey; sosyal hareketlilik mekanizmaları sağlamak, öğrenciler ve yerel gelişim için faydalı olan ders kitaplarının derlenmesine katkıda bulunmak, daha fazla öğretmen yetiştirmek ve okullara destek olmaktır. Bu durum âdem-i merkeziyetçilik ve merkezileşme arasında dengeli bir çabayı gerektirmektedir: Birincisi, azınlıkların çocuklarının eğitime katılımlarını arttırmayı, ekonomik ve politik olarak onları güçlendirmeyi amaçlarken; ikincisi, eğitimciler, politikacılar ve toplumun farklı kesimlerindeki liderler arasında genel bir işbirliğini gerektirmektedir. Aynı zamanda bu çabaların da, azınlık ekonomilerinin modernizasyon sürecine ve teknolojinin gelişimine, bu sürecin bir parçası olarak iki dilli eğitime entegre edilebilmesi gerekmektedir. Her şeyden önce, azınlık eğitiminin önemi göz önüne alındığında, iki dilli eğitime öncelik verilmelidir.

Saydığımız tüm bu hususların altında yatan ise herkes için eşitlik ilkesinin teşvikidir. Bu ilke; dil, kültür ve tarihte çoğulcu bir görüş ve azınlık insanlarının medeniyete yaptıkları ve yapabilecekleri katkıların tanınması için bir çağrıda bulunmaktadır. Bu doğrultuda azınlık öğrencileri için çok dilli eğitim, Han öğrencileri için ise çok kültürlü eğitim okullar tarafından da desteklenmeli ve bu süreç iki yönlü olarak işlevsel bir hale getirilebilmelidir.

\section{SUMMARY}

Bilingualism, in its most familiar definition, is the phenomenon of speaking and understanding two or more languages. Besides, it takes its origins from sociology and linguistics. Although bilingualism may seem simple in the literal sense, it is quite complex in essence. It can affect the future lives of societies positively and negatively. Especially minority nations have been affected by this issue both positively and negatively throughout the history. China is a country of 56 ethnic minority groups and every minority living in this country also has a language of their own. However, Mandarin is used as the majority language in China. In order to popularize the use of Mandarin, certain education policies have been put forward by the government in the country. 
The main aim of this study is to analyze bilingualism and its positive-negative consequences over minorities in China. For this purpose, the 20th century Chinese education policies towards national minorities were also emphasized. The continuity of Chinese education policies has been researched according to China's 2010-2020 medium and long term education reform and national development plan.

The main questions in the emergence of this study are: Does bilingualism really increase the educational level of minorities or lead to assimilation? What can be done for more effective bilingualism learning? In order to give concrete answers to these questions, examples are frequently used in the study. In addition, it is aimed to contribute to the development of bilingualism education in line with these questions.

This study can be defined as a qualitative research based on the government's decisions and laws in minority education. In addition to the attitude of the government on this issue, the perspectives of Chinese scholars on bilingual education were investigated, bilingual education policies and their implementation in Chinese minority schools were examined.

Findings reached in this study are as follows: if bilingualism education does not start at an early age, it can be more diffucult later on. Problems of bilingualism education can be reduced with reliable education planning. Not paying enough attention to bilingualism education may cause assimilation in minorities and loss of self-confidence in the individual. China has made some educational plans in recent years that showing that it cares about minorities rather than trivializing them.

There are no countries in the world where there are no minorities and so the constitution of each country speaks of equality. Equality means that people are treated the same or equally, regardless of the religion, language, color or culture. Consequently, bilingualism education in the world should be applied not only to minorities but also to majority. In this way bilingualism can be used to create respect for cultural differences by eliminating communication disconnections caused by language differences.

Makale Bilgileri

$\begin{array}{ll}\text { Etik Kurul Kararı: } & \text { Etik Kurul Kararından muaftır. } \\ \text { Katılımoı Rızası: } & \text { Katılımcı Yok } \\ \text { Mali Destek: } & \text { Çalışma için herhangi bir kurum ve projeden mali destek } \\ & \text { alınmamıştır. } \\ \text { Çıkar Çatışması: } & \text { Çalışmada kişiler ve kurumlar arası çıkar çatışması } \\ & \text { bulunmamaktadır. } \\ \text { Telif Hakları: } & \text { Telif hakkına sebep olacak bir materyal kullanılmamıştır. }\end{array}$

Article Information

Ethics Committee Approval:

Informed Consent:

Financial Support:

Conflict of Interest:

Copyrights:
Exempt from the Ethics Committee Decision.

No participant

No financial support from any institution or project.

No conflict of interest.

No material subject to copyright is included. 


\section{KAYNAKÇA}

Blachford, D. R. (1997). "Bilingual Education in China." J. Cummins \& D Corson (eds). Encyclopedia of Language and Education. Volume 5. Netherlands: Springer Science+Business Media, B.V. 157-165.

Chen, K. et al. (1996). Wenshan, Honghe Zizhizhou Hani Miao Lahuzu Jiaoyu Fazhan Diaocha Yu Yanjiu (文山、红河自治州哈尼、苗、拉祜族教育发展调查与研 究). Minzu Jiaoyu Yanjiu (民族教育研究)- (Journal of Research on Education for Ethnic Minorities), 1, 40-47.

Chen, X. (1995). “Shuangyu Jiaoxue" Guanjian (“双 语教学”管 见). Minzu Jiaoyu Yanjiu (民 族教育研究)- (Journal of Research on Education for Ethnic Minorities), 1, 7- 56.

Cleghorn, A., Merritt, M. ve Abagi, J. (1989). Language Policy and Science Instruction in Kenyan Primary Schools. Comparative Education Review Journal, 33 (1), 21.

Gladney, D.C. (1994). Ethnic Identity in China: The New Politics of Difference. W.A. Joseph (Ed.), China Briefing içinde (s. 92-171). Boulder: Westview Press.

Guan, X. (1995). Zongguo Shaoshu Minzu Shuangyu Jiaoyu Shiyan Diaocha yu Sikao (中 国 少数民族双语教育实验调查与思考). Minzu Jiaoyu Yanjiu (民族教育研究)(Journal of Research on Education for Ethnic Minorities), 4, 15-20.

He, J. (1995). Xibozu Xuexiao Shixin Shangyu Jiaoxue de Yiyi, Chengjiu Ji Zhuyao Huanjie ( 锡伯族学校施行双语教学的意义、成就及主要环节). Minzu Jiaoyu Yianjiu (民 族教育研究)- (Journal of Research on Education for Ethnic Minorities), 3, 9- 77.

Heath, S.B. (1981). English in Our Language Heritage. C.A. Ferguson \& S. B. Heath (Ed), Language in The USA içinde (s. 6-20). Cambridge: Cambridge University Press.

Lin, J. (1993). Ethnic Relationships and Minority Education in Guangxi, China: A Case Study. Canadian and International Education. 22(1), 5-21.

Lin, J. (1996, Mart). Identity and Discrimination: Minorities in China. Paper presented The Comparative and International Education Society Annual Conference. Williamsburg: Virginia.

Lin, J. (1997). "Policies and Practices of Bilingual Education for the Minorities in China". Journal of Multilingual and Multicultural Development. Vol. 18. No. 3. s. 193-205.

Lin, J. ve Zhou, Y. (1996, Mart). Minority Policy and Minority Education: Reform in Guangxi, China. Paper presented in The Comparative and International Education Society Annual Conference. Williamsburg: Virginia.

Liu, B. (1993). “The importance of minority nationality mother tongue in bilingual education and its development prospect". Shaoshu minzu muyu zai shuangyu jiayu zhong de yiyi jiqi fazhan qianjing (少数民族母语在双语教育中的意义及其发展前景). Minzu Yuwen (民 族语文)- (Minority Languages of China),3, 8- 75.

Outline of China's National Plan for Medium and Long-term Education Reform and Development. (2010, 9 Temmuz). Outline of China's National Plan for Medium and Longterm Education Reform and Development 2010-2020. s. 23-37. Erişim adresi: http://ncee.org/wp-content/uploads/2016/12/Sha-non-AV-5-China-Education-Plan-20102020.pdf. (Erişim tarihi: 16.12.2020)

SEFAD, 2021; (45): 49-62 
People's Daily. (Overseas edition). (1995, 21 Ekim). China Gives Priority to Development of Minority Education. s. 3.

People's Government of Yanbian Prefecture of Jilin Province .(1992). Gaohao Shuangyu Jiaoxue Tigao Minzu Jiaoyu Zhiliang (搞好双语教学提高民族教育质量). Zhongguo Minzu Jiaoyu (中国民族教育). 3, 8- 96.

Shama, J. (1991). Minzu Wenzi Jiaocha Jianshe Jiqi Wenti (民族文字较差建设及其问题/ The development of minority language textbooks and problems). Zhongguo Minzu Jiaoyu (中 国民族教育). 2, 7- 55 .

Stites, R. (1992, Mart). Mother Tongue Literacy and Modernisation: Problems in The Theory and Practice of Bilingual Education in The People's Republic of China. Comparative and International Education Society Annual Conference, Annapolis: MD.

Tawakkul, D. (1999). A Study of Chinese Policy towards National Minorities with Reference to Higher Education: A Case Study of the Central University for Nationalities. (Doktora Tezi). Erişim Adresi: https://core.ac.uk/download/pdf/14344063.pdf. (Erişim Tarihi: 17.12.2020)

The State Council The People's Republic of China. (1982). Guo Hua Renmin Gongheguo Zhongyang Renmin Zhengfu (国华人民共和国中央人民政府). Constitution of the People's Republic of China. Chapter 1. Article 4. Erişim adresi: http://english.www.gov.cn/archive/lawsregulations/201911/20/content_WS5ed8856ec6d 0b3f0e9499913.html. (Erişim tarihi: 14.12.2020)

The State Council The People's Republic of China. (2002). Guo Hua Renmin Gongheguo Zhongyang Renmin Zhengfu (国华人民共和国中央人民政府). Damıştay，Reformu Derinleştirme ve Etnik Eğitimin Gelişimini Hızlandırma Kararı (国务院关于深化改革加快发 展民族教育的决定)。 No. 14 . Bölüm. 3. Karar. 6. Erişim adresi: http://www.gov.cn/gongbao/content/2002/content_61658.htm. (Erişim tarihi: 15.12.2020)

Wang, Q. (1995). Hanyu Ketang Jiaoxue de Jiaoji Hua Chutan (汉语课堂教学的交际化 初 探). Minzu Jiaoyu Yanjiu (民族教育研究)- (Journal of Research on Education for Ethnic Minorities), 3, 6- 75.

Wang, Y. \& Phillion, J. (2009). “Minority Language Policy and Practice in China: The Need for Multicultural Education". International Journal of Multicultural Education. Vol.11. No.1. 1-14.

Wu, L. (1989). Yunnan Shuangyu Jiaoyu Zhi Wojian (云南双语教育之我见/ My Perspective on Bilingual Education in Yunnan). Minzu Yuwen (民族语文), 11, 69-70.

Yang, M. \& Xi, S. (1995) Baizu Ba, Han Shuangyu Jiaoxue Shiliu Zi Fangzhen Shishi Chutan ( 白族白、汉双语教学十六字方针实施初探). Minzu Jiaoyu Yanjiu (民族教育研究)(Journal of Research on Education for Ethnic Minorities), 1, 58-62.

Zhang, Q. (1992). Luetan Shuangyu Jiaoxue zhong de Yuyan Goutong Yu Wenhua Goutong (略谈双语教学中的语言沟通与文化沟通/ Briefly on Language and Cultural Communication in Bilingual Teaching). Minzu Yuwen (民族语文), 4, 7- 63.

Zhou, M. (2003). Multilingualism in China: The Politics of Writing Reforms for Minority Languages 1949-2002. J. A. Fishman (ed.). Berlin: Mouton de Gruyter. 89.

Zhou, Q. (1991). Zhongguo Shuangyu Jiaoyu Leixing (中国双语教育类型/ The Type of Bilingual Education in China). Minzu Yuwen (民族语文), 3, 65-69. 